Letter to the Editor

\title{
Under pressure: A cohort analysis of elevated intraocular pressure in long-term vascular endothelial growth factor inhibitor treatment
}

Matthew McCartney MBBS, Beverley Curry PhD, Paul Sanfilippo PhD and Nitin Verma FRANZCO

Sydney Eye Hospital, 8 Macquarie St, Sydney NSW 2000; University of New South Wales Sydney NSW 2052; Hobart Eye Surgeons, 182 Argyle Street Hobart TAS 7000; University of Tasmania, Churchill Ave, Hobart TAS 7005; University of Sydney, Camperdown NSW 2006

Correspondence: Dr Matthew McCartney, 13 1/7 Pelican St Surry Hills NSW 2010, Australia

Email: matt.hari.mcc@gmail.com

Received 27 J une 2020; accepted 10 J uly 2020

Funding sources / Financial disclosure: None

Conflict of interest: None

Ethics statement: The study was performed according to principles of Good Clinical Practice (GCP) and the Declaration of Helsinki; ethical approval was obtained from the Tasmanian Health and Medical Human Research Ethics Committee (H0017131).

This is the author manuscript accepted for publication and has undergone full peer review but has not been through the copyediting, typesetting, pagination and proofreading process, which may lead to differences between this version and the Version of Record. Please cite this article as doi: 10.1111/ceo.13831

This article is protected by copyright. All rights reserved. 
The current first line treatment for macular oedema associated with age-related macular degeneration (AMD) or diabetic retinopathy (DR) is intravitreal vascular endothelial growth factor (VEGF) inhibitors. ${ }^{1-2}$ Some evidence suggests an increased risk of elevated intraocular pressure (IOP) with anti-VEGF treatment. A recent metaanalysis highlighted a possible two-fold increased risk of elevated IOP in eyes receiving anti-VEGF treatment, with increased risk in patients with glaucoma. ${ }^{3}$

Several hypotheses exist exploring the possible association of repeated intraocular injections and the development of elevated IOP. These include injection-related complications from mechanical obstruction of the trabecular meshwork or Schlemm's canal via metabolised byproducts; chronic structural changes secondary to recurrent transient pressure elevation; drug-induced complications as well as possible injection associated trabeculitis or uveitis. $^{3}$

Using a retrospective cohort of Tasmanian patients with a range of conditions treated with anti-VEGF treatment, the authors present a long-term analysis to review the incidence and prevalence of elevated IOP and any associated risk factors. 1086 eyes of 543 patients ( 321 women and 222 men) with eyes, treated with anti-VEGF treatment from J anuary 2007 to December 2017 was studied. A total of 20886 injection events were recorded in 4350 person-years of data. The study was performed according to principles of Good Clinical Practice (GCP) and the Declaration of Helsinki; ethical approval was obtained from the Tasmanian Health and Medical Human Research Ethics Committee (H0017131). 
The primary outcome was incidence of elevated IOP after commencing treatment. Secondary outcomes included the incidence of elevated IOP secondary to diagnosis classification, number of injections, treating agent (bevacizumab, ranibizumab or aflibercept), treatment vs control (fellow, untreated, eye) and pre-treatment demographic data and comorbidities. For the purposes of analysis of treating agent, only patients who received single agent-treatment were analysed.

Elevated IOP was defined as IOP $>22 \mathrm{mmHg}$ on 2 consecutive reviews, an increase in $6 \mathrm{mmHg}$ from baseline on 2 consecutive reviews, or a single measure of $>26$ $\mathrm{mmHg}$ at any review. Inclusion criteria were an age greater than 18 and a minimum of 12 months of treatment. Exclusion criteria included intraocular surgery in the study eye within 2 months of baseline and inflammation of any kind at the time of anti-VEGF initiation.

The pooled prevalence of elevated IOP in the cohort was 117 of 543 patients ( $21.5 \%)$, with a calculated incidence of 26.8 cases per 1000 person-years. Univariate analysis of individual retinal pathologies on anti-VEGF treatment demonstrated no statistically significant hazard ratio (HR) for the development of elevated IOP (Table 1).

\begin{tabular}{|l|l|l|l|l|l|}
\hline $\begin{array}{c}\text { Treated } \\
\text { Pathology }\end{array}$ & $\begin{array}{l}\text { Number } \\
\text { of Eyes }\end{array}$ & $\begin{array}{c}\text { Observation } \\
\text { Period } \\
\text { (person- } \\
\text { years) }\end{array}$ & $\begin{array}{c}\text { Elevated } \\
\text { IOP } \\
\text { Episodes }\end{array}$ & $\begin{array}{c}\text { Incidence } \\
\text { Rate } \\
\text { (\% of } \\
\text { cohort) }\end{array}$ & $\begin{array}{c}\text { Statistical } \\
\text { significance of } \\
\text { Elevated I OP Risk } \\
\text { (p value (CI) })\end{array}$ \\
\hline AMD & 450 & 2009.15 & 42 & $0.0196(12)$ & $0.208(0.496-1.165)$ \\
\hline DMO & 160 & 482.69 & 23 & $\begin{array}{l}0.0473 \\
(22.1)\end{array}$ & $0.083(0.942-2.650)$ \\
\hline RVO & 40 & 197.71 & 9 & $\begin{array}{l}0.0448 \\
(17.3)\end{array}$ & $0.163(0.817-3.341)$ \\
\hline CNVM & 18 & 28.29 & 1 & $0(11.1)$ & $0.949(0.135-8.473)$ \\
\hline CSR & 2 & 5.28 & 0 & $0.0(0)$ & Nil result \\
\hline $\begin{array}{l}\text { Idiopathic } \\
\text { CMO }\end{array}$ & 2 & 19.42 & 1 & $0.1029(100)$ & $0.160(1.306-13.459)$ \\
\hline Untreated Eye & 414 & 1518.37 & 41 & $0.0270(20)$ & $0.942(0.702-1.463)$ \\
\hline
\end{tabular}




\begin{tabular}{|l|l|l|l|l|l|}
\hline Total & 1086 & 4350.75 & 117 & $\begin{array}{l}0.0268 \\
(21.5)\end{array}$ & - \\
\hline
\end{tabular}

Table 1: Elevated IOP incidence, stratified by disease (univariate analysis).

$\mathrm{Cl}$ - Confidence Interval, AMD - Age-Related Macular Degeneration, DMO - Diabetic Macular Oedema, RVO - Retinal Vein Occlusion, CNVM - Choroidal Neovascular Membrane, CSR - Central Serous Retinopathy, CMO - Cystoid Macular Oedema

Comparison with untreated fellow eyes did not identify any evidence of an increased risk of elevated IOP in eyes treated with anti-VEGF treatment (HR 1.01, p 0.91). This was also shown in multivariate analysis (HR 0.978, Cl 0.674-1.419).

Pre-existing glaucoma was identified on multivariate analysis as an independent risk factor for developing elevated IOP (HR of 3.44, $p<0.001$ ) while pseudophakia was associated with a reduced risk of elevated IOP (HR of $0.58, p<0.05$ ) (Table 2). Otherwise, no other secondary outcome measure demonstrated a statistically significant association for an increased or decreased HR of elevated IOP.

\begin{tabular}{|l|c|c|c|c|c|c|}
\hline $\begin{array}{c}\text { Cohort } \\
\text { Characteristic }\end{array}$ & $\begin{array}{c}\text { Number } \\
\text { of Eyes }\end{array}$ & $\begin{array}{c}\text { Observation } \\
\text { Period } \\
\text { (person- } \\
\text { years) }\end{array}$ & $\begin{array}{c}\text { Elevated } \\
\text { I OP } \\
\text { Episodes }\end{array}$ & $\begin{array}{c}\text { I ncidence } \\
\text { Rate }\end{array}$ & $\begin{array}{c}\text { Hazard } \\
\text { Ratio }\end{array}$ & $\begin{array}{c}\text { Statistical } \\
\text { significance of } \\
\text { Hazard Ratio } \\
\text { (p value (CI) ) }\end{array}$ \\
\hline Anti-VEGF & 1086 & 4350.75 & 117 & & 0.997 & $0.908(0.674-1.419)$ \\
\hline Age (increase) & 1086 & 4350.75 & 117 & NA & 0.984 & $0.058(0.968-1.001)$ \\
\hline Male gender & 444 & 1715.87 & 59 & 0.0343 & 1.19 & $\begin{array}{l}0.258(0.874- \\
1.178)\end{array}$ \\
\hline Diabetes & 240 & 789.46 & 35 & 0.0443 & 1.38 & $\begin{array}{l}0.218(0.827- \\
2.303)\end{array}$ \\
\hline Glaucoma & 92 & 366.69 & 27 & 0.0736 & $\mathbf{3 . 4 4}$ & $\frac{\mathbf{0 . 0 0 1}(2.127-}{5.576)}$ \\
\hline Pseudophakia & 350 & 1761.83 & 31 & 0.1759 & $\mathbf{0 . 5 8}$ & $\frac{\mathbf{0 . 0 2 6}}{0.927)}(0.365-$ \\
\hline
\end{tabular}


Table 2: Elevated IOP incidence, stratified by pre-treatment demographic details and comorbidities (multivariate analysis)

Cl - Confidence Interval.

While sustained elevation intraocular pressure is demonstrable in patients receiving anti-VEGF treatment, the incidence of elevated IOP is not greater than in untreated fellow eyes of the same patients or related to total number of injections or underlying pathology. Pre-existing glaucoma was the identifiable significant risk factor to the development of elevated IOP, while pseudophakia was also found to be an independent protective factor.

Zhou et al's meta-analysis demonstrated an estimated all-study prevalence of $4.7 \%$, (CI 2-11\%). ${ }^{3}$ The authors hypothesise our greater prevalence of elevated IOP was association with greater proportional inclusion of patients with glaucoma. The earlier MARI NA ${ }^{4}$ and ANCHOR ${ }^{2}$ trials demonstrated a similar pooled prevalence of elevated IOP of approximately $26.1 \%$. Similarly, Wehrli et al's 2012 cohort analysis demonstrated an elevated IOP incidence of 0.017 (Cl 0.002-0.031) and no statistically significant difference between injected and untreated eyes. ${ }^{5}$

Limitations of the study include the retrospective, non-randomised, and uncontrolled nature of the cohort. Data collection was occasionally limited by prior incomplete data entry and non-uniform follow-up and repeat injections times limit direct the accuracy of direct comparisons between patients and pathologies, as well as the varied size of pathological subgroups within the study limiting the significance of results. 
Regardless of the indication, regular intravitreal anti-VEGF treatment with bevacizumab, ranibizumab or aflibercept do not appear to be associated with an increased risk of elevated IOP in the long-term, other than a previous history of glaucoma. The intraocular pressure of patients with a history of glaucoma should be monitored carefully when being treated with intravitreal anti-VEGFs.

\section{Acknowledgments}

The authors thank the staff of Hobart Eye Surgeons for their help in obtaining data from medical records. 


\section{REFERENCES}

1. Zhao Y, Singh RP. The role of anti-vascular endothelial growth factor (antiVEGF) in the management of proliferative diabetic retinopathy. Drugs Context. 2018; 7:212532

2. Kovach J L, Schwartz SG, Flynn HW, Jr., Scott IU. Anti-VEGF Treatment Strategies for Wet AMD. J Ophthalmol. 2012;2012:786870.

3. Zhou Y, Zhou M, Xia S, Jing Q, Gao L. Sustained Elevation of Intraocular Pressure Associated with Intravitreal Administration of Anti-vascular Endothelial Growth Factor: A Systematic Review and Meta-Analysis. Sci Rep. 2016;6:39301.

4. Rosenfeld PJ, Brown DM, Heier JS, Boyer DS, Kaiser PK, Chung CY, et al. ranibizumab for Neovascular Age-Related Macular Degeneration. New England J ournal of Medicine. 2006;355(14):1419-31.

5. Wehrli SJ, Tawse K, Levin MH, Zaidi A, Pistilli M, Brucker AJ. A lack of delayed intraocular pressure elevation in patients treated with intravitreal injection of bevacizumab and ranibizumab. Retina (Philadelphia, Pa). 2012;32(7):1295-301. 


\section{University Library}

\section{- M M I N E R VA \\ A gateway to Melbourne's research publications}

Minerva Access is the Institutional Repository of The University of Melbourne

Author/s:

McCartney, M;Curry, B;Sanfilippo, P;Verma, N

Title:

Under pressure: A cohort analysis of elevated intraocular pressure in long-term vascular endothelial growth factor inhibitor treatment.

Date:

2020-11

Citation:

McCartney, M., Curry, B., Sanfilippo, P. \& Verma, N. (2020). Under pressure: A cohort analysis of elevated intraocular pressure in long-term vascular endothelial growth factor inhibitor treatment.. Clin Exp Ophthalmol, 48 (8), pp.1104-1106. https://doi.org/10.1111/ ceo.13831.

Persistent Link:

http://hdl.handle.net/11343/276179 